\title{
Topical loperamide for the treatment of localized neuropathic pain: a case report and literature review
}

DJ Kopsky'

AK Bhaskar ${ }^{2}$

HJ Zonneveldt ${ }^{3}$

JM Keppel Hesselink ${ }^{4}$

'Institute for Neuropathic Pain, Amsterdam, the Netherlands; ${ }^{2}$ Pain Management Centre, Charing Cross Hospital Imperial Healthcare NHS Trust, London, UK; ${ }^{3}$ Anesthesiology and Pain Department, Westfriesgasthuis, Hoorn, the Netherlands; ${ }^{4}$ Institute for Neuropathic Pain, Bosch en Duin, the Netherlands
Correspondence: DJ Kopsky Institute for Neuropathic Pain, Vespuccistraat 64-III, 1056 SN,

Amsterdam, the Netherlands

Tel +3 I62 867 I847

Email info@neuropathie.nu
This article was published in the following Dove Press journal:

Journal of Pain Research

\begin{abstract}
Peripheral nerve damage can result in neuronal hyperexcitability, resulting in neuropathic pain. Localized neuropathic pain is confined to a specific area not larger than a letter-size piece of paper. Topical analgesics are increasingly popular for the treatment of localized neuropathic pain because systemic agents for managing neuropathic pain often produce undesirable and intolerable side effects. Commonly used agents for topical use are amitriptyline, baclofen, ketamine and lidocaine; however, these agents do not always give the desired analgesic effect in some patients. We report for the first time a patient with chronic idiopathic axonal polyneuropathy and intractable localized neuropathic pain treated successfully with loperamide $5 \%$ cream. After application of loperamide $5 \%$ cream, the patient reported a complete reduction of pain within $30 \mathrm{mins}$, lasting for $2.5 \mathrm{hrs}$. Subsequently, the patient was able to reduce his daily intake of oxycodone, while using topical loperamide for pain relief. Loperamide is a nonprescription opioid agonist, commonly used against diarrhea. As a topical formulation, it is preferable over other opioids due to its low systemic bioavailability and low risk of crossing the blood-brain barrier. Peripheral upregulation and sensitization of opioid receptors at peripheral nerve endings and perhaps at other cell populations in the epidermis might be targets of topical loperamide.
\end{abstract}

Keywords: localized neuropathic pain, loperamide, topical agents, analgesia

\section{Introduction}

Peripheral nerve damage can result in neuronal hyperexcitability, resulting in neuropathic pain. ${ }^{1}$ Peripheral nerves can be affected by metabolic damage, toxins and medications. ${ }^{1}$ Localized neuropathic pain (LNP) is confined to a specific area not larger than a letter-size piece of paper. ${ }^{2}$ Averaging across all neuropathic pain conditions approximately $60 \%$ of the patients have LNP. ${ }^{2}$ Topical analgesics are becoming increasingly popular with most patients for the treatment of LNP, because nearly no side effects are present when used properly. Neuropathic pain agents taken orally for analgesia target the central nervous system (CNS), commonly produce undesirable and often unacceptable side effects. ${ }^{3}$ These CNS side effects include somnolence, sedation, confusion and cognitive disturbances. Other side effects, particularly with gabapentinoids, include weight-gain, and some patients report intolerance to the dryness of mouth and drowsiness from the tricyclic antidepressants such as amitriptyline. Hyperhidrosis, nausea, dry mouth, fatigue and gastrointestinal disturbances have been reported as reasons for patients discontinuing serotonin-norepinephrine reuptake inhibitors like duloxetine. ${ }^{4,5}$ In 
Table I (Co)-analgesics and their concentrations alone or in combinations in topical formulations

\begin{tabular}{|c|c|c|}
\hline Agents & Concentration in \% & Main mechanism of action \\
\hline Ambroxol ${ }^{7}$ & 20 & TTX-resistant sodium channel blocker \\
\hline Amitriptyline ${ }^{8}$ & $1,2,5,10$ & Inhibition of sodium, potassium, calcium voltage-gated ion channels \\
\hline Baclofen $^{7}$ & 2,5 & GABA-B receptor agonist \\
\hline Capsaicin $^{7}$ & $0.025-0.075,8$ & $\begin{array}{l}\text { Desensitization of transient receptor } \\
\text { potential vanilloid Ichannel }\end{array}$ \\
\hline Clonidine $^{7}$ & $0.1,0.2$ & $\alpha 2$-adrenergic agonists \\
\hline Gabapentin $^{7}$ & 6 & Inhibition of $\alpha 2 \delta$ subunits of calcium channels \\
\hline Ketamine 9 & $0.5,1,1.5,5,2,10,20$ & Inhibition of glutamate $\mathrm{N}$-methyl-D-aspartate receptor \\
\hline Lidocaine $e^{7,9}$ & $2,3,5,8,10$ & Inhibition voltage-gated sodium channels \\
\hline Phenytoin ${ }^{10-13}$ & $5,10,20,30$ & Stabilization of voltage-gated sodium channels \\
\hline
\end{tabular}

comparison to systemic agents, compounded topical preparations of such agents are well tolerated by patients. Most patients respond well to commonly used topical agents like amitriptyline, ketamine, clonidine, lidocaine and baclofen (see Table 1 for known topical analgesics the treatment of neuropathic pain). ${ }^{6}$ However, there are still patients who would not have a favorable analgesic response with these agents. In such patients with intractable pain not responding to more obvious topical analgesics, other treatment strategies have to be explored.

In this report, we describe a case of chronic idiopathic axonal polyneuropathy (CIAP) with intractable LNP treated successfully with topical application of loperamide 5\% cream. CIAP is a slowly progressive distal symmetric sensory or sensorimotor polyneuropathy without a known cause, and approximately one-third of the patients have neuropathic pain in the feet sometimes extending into the lower legs. ${ }^{14} \mathrm{In}$ neuropathic pain mice models, the concentration of $\mu$-opioid receptors (MOR) was elevated the skin. ${ }^{15,16}$ Therefore, we chose loperamide topically as a nonprescription MOR agonist used for the symptomatic management of diarrhea. ${ }^{17}$ After oral intake, loperamide is well absorbed from the gastrointestinal tract and is almost completely extracted and metabolized by cytochrome P450 (particularly CYP3A4) in the liver. ${ }^{17}$ As a result, the bioavailability after oral intake is only around $0.3 \% .^{3}$ Loperamide has a considerably higher binding affinity to the MOR than to the $\delta$-opioid receptor (DOR) or the $\kappa$-opioid receptor (KOR), with $\mathrm{K}_{\mathrm{i}}$ values of 3.3, 48 and $1156 \mathrm{nM}$, respectively. ${ }^{18}$ The higher binding affinity a drug has to a receptor, the more the drug influences the receptor. Although loperamide is highly lipophilic, the efflux membrane transporter in the blood-brain barrier, P-glycoprotein, actively extrudes loperamide from the CNS. ${ }^{17}$ The use of topical loperamide for the treatment of peripheral neuropathic pain has never been described in published literature. The patient has given his written informed consent, and no institutional approval is required to publish his case anonymously.

\section{Case report}

A 63-year-old man suffered from neuropathic pain due to CIAP since 2013. The pain started in the distal parts of both feet, where the size of the pain area gradually expanded over time, up to $10 \mathrm{~cm}$ above the ankles in the following years. He scored 8 out of 10 on the Douleur Neuropathique 4 questionnaire (DN-4), which indicated that clinical signs and symptoms were of neuropathic nature and origin. In his own words, the patient characterized the pain as burning, tingling, pins and needles, electric shocks and numbness. Despite being on analgesics and neuropathic pain agents, he scored his pain intensity as 7 on the 11-point numerical rating scale (NRS). At that time, he used amitriptyline $25 \mathrm{mg}$ once daily and oxycodone $10 \mathrm{mg}$ twice daily. Oxycodone $10 \mathrm{mg}$ only reduced his pain temporarily. Previously, pregabalin and neuraxial blockade at L4 and L5 did not have any effect on the pain. In addition to his severe pain, it was noticed that his sense of maintaining balance was poor. Physical examination further revealed loss of vibration sense up to bothknees, absence of bilateral ankle jerk reflexes, loss of temperature discrimination, hypoesthesia for pinprick and touch and allodynia after soft stroking with a hand up to a length of $20 \mathrm{~cm}$ beneath the knees. Baclofen $5 \%$ cream and amitriptyline $10 \%$ cream reduced his pain from a score of 7 to 5 on the NRS, but the patient did not feel this provided him adequate and meaningful analgesia. On consultation, a single-blind response test with amitriptyline $10 \%$ cream on the right foot and loperamide $5 \%$ 
cream on the left foot was performed. After 30 mins, the patient reported a pain reduction of 7 to 5 on the NRS on the amitriptyline $10 \%$ cream applied area and a reduction from 7 to 3 on the loperamide 5\% cream applied area. Because loperamide 5\% cream had clearly a more pain reducing effect, loperamide 5\% cream was prescribed.

Following a period of 3 days of open test application with loperamide $5 \%$ cream, in a telephone call, the patient reported back that the neuropathic pain was completely resolved. The onset of the analgesic effect was within 30 mins of initial application. Over the course of the following weeks, the patient applied loperamide 5\% cream once or twice daily for symptomatic relief and the pain-reducing effect lasted for about $2.5 \mathrm{hrs}$ following each application. More daily applications were not practical. Due to the positive and meaningful reduction of the pain, the patient could reduce his oral oxycodone intake by $50 \%$. The patient did not report nor experience any side effects from the topical application of loperamide $5 \%$ cream.

\section{Discussion}

The authors feel that to the best of our knowledge, we have described the first case of LNP treated successfully with topical loperamide $5 \%$ cream as a single agent. Single-blind response test (SIBRET) performed with amitriptyline $10 \%$ cream and loperamide 5\% cream showed the superiority of loperamide $5 \%$ cream over amitriptyline $10 \%$ cream in this patient. When testing the effect in naïve patients with topical analgesics, SIBRET with placebo cream is preferable to rule out initial placebo responders. There is a case report of one patient with complex regional pain syndrome pain successfully treated with topical application of a combination gel consisting of ketamine 15\%/loperamide 5\%/guaifenesin $10 \% /$ lidocaine $2 \%{ }^{19}$ For the management of acute pain due to finger lancing, loperamide $5 \%$ gel has been evaluated in a double-blind randomized clinical trial (NCT02711891). ${ }^{20}$ In this study, 34 adult volunteers received 2 lancings. Ten minutes following the first lance, loperamide $5 \%$ gel or placebo gel was applied onto the lanced fingertip. A repeat lance followed in 30 mins. loperamide $5 \%$ gel produced a statistically significant decrease in visual analogue scale (VAS) $(1.9 \pm 1.4$ vs $4.2 \pm 2.4 p=0.002)$ as compared to the placebo gel. At $24 \mathrm{hrs}$, the proportion of participants who stated no pain (loperamide $82 \%$, placebo $29 \%$ ), no sensitivity to light touch (loperamide $82 \%$, placebo $35 \%$ ) and no sensitivity to pressure (loperamide $88 \%$, placebo $29 \%$ ) were significantly greater in the loperamide 5\% gel group.

Results from one animal study indicate that loperamide creams with the concentration of $0.5 \%, 1.7 \%$ and $5 \%$ had a dose-dependent anti-hyperalgesic effect in a thermal injury rat model. ${ }^{21}$ In a second animal study, using a fullthickness burn rat model, topical loperamide 5\% significantly increased mechanical thresholds, prevented sensitization of uninjured skin and reduced burn-induced ectopic discharge of the recorded nociceptive fibers. ${ }^{22}$ The mechanism of action of topical loperamide in peripheral neuropathic pain is most probably by influencing MORs at the nerve endings of the nociceptors, and perhaps additionally, on other structures in the epidermis (for example, keratinocytes and immune-competent cells). ${ }^{23}$ In several neuropathic pain models, an enhanced expression of opioid receptors has been documented at the nerve lesion site and in paw skin. ${ }^{24}$ Our postulation is that topical loperamide acts on MORs at nociceptors in the skin and other cell-populations such as keratinocytes and immunecompetent cells. Topical loperamide $5 \%$ formulation might be a new useful addition as a potential therapeutic option in the treatment of therapy-resistant LNP. The optimal concentration of loperamide cream will have to be elucidated in N-of-1 studies and/or dose-finding studies.

\section{Conclusion}

In our case report, loperamide $5 \%$ cream proved effective in reducing intractable neuropathic pain which did not respond to systemic analgesics and other trials of topical agents. Clinicians facing patients with intractable LNP, not responding on oral analgesics or common compounded topical analgesics, can broaden their armamentarium with topical loperamide. The use of SIBRET in symmetrical polyneuropathy to determine true responders on topical loperamide can be very helpful. ${ }^{25}$ Well-designed doubleblinded randomized controlled trials will further elucidate the role of topical loperamide as an option for the management of LNP.

\section{Disclosure}

DJ Kopsky and Prof. Dr JM Keppel Hesselink report patents pending on topical phenytoin. The authors report no other conflicts of interest in this work. 


\section{References}

1. Meacham K, Shepherd A, Mohapatra DP, Haroutounian S. Neuropathic pain: central vs. peripheral mechanisms. Curr Pain Headache Rep. 2017;21(6):017-0629. doi:10.1007/s11916-0170629-5

2. Mick G, Baron R, Finnerup NB, et al. What is localized neuropathic pain? A first proposal to characterize and define a widely used term. Pain Manag. 2012;2(1):71-77. doi:10.2217/pmt.11.77

3. Gharibian D, Polzin JK, Rho JP. Compliance and persistence of antidepressants versus anticonvulsants in patients with neuropathic pain during the first year of therapy. Clin J Pain. 2013;29 (5):377-381. doi:10.1097/AJP.0b013e31825e45d9

4. Skljarevski V, Desaiah D, Liu-Seifert H, et al. Efficacy and safety of duloxetine in patients with chronic low back pain. Spine. 1976;35 (13):E578-E585. doi:10.1097/BRS.0b013e3181d3cef6

5. Irving G, Tanenberg RJ, Raskin J, Risser RC, Malcolm S. Comparative safety and tolerability of duloxetine vs. pregabalin vs. duloxetine plus gabapentin in patients with diabetic peripheral neuropathic pain. Int J Clin Pract. 2014;68(9):1130-1140. doi:10.1111/ ijcp. 12452

6. Knezevic NN, Tverdohleb T, Nikibin F, Knezevic I, Candido KD. Management of chronic neuropathic pain with single and compounded topical analgesics. Pain Manag. 2017;7(6):537-558. doi: 10.2217/pmt-2017-0020

7. Coderre TJ. Topical drug therapeutics for neuropathic pain. Expert Opin Pharmacother. 2018;19(11):1211-1220. doi:10.1080/14656566. 2018.1501026

8. Kopsky DJ, Hesselink JM. High doses of topical amitriptyline in neuropathic pain: two cases and literature review. Pain Pract. 2012;12(2):148-153. doi:10.1111/j.1533-2500.2011.00477.x

9. Kopsky DJ, Keppel Hesselink JM, Bhaskar A, Hariton G, Romanenko V, Casale R. Analgesic effects of topical ketamine. Minerva Anestesiol. 2015;81(4):440-449.

10. Kopsky DJ, Keppel Hesselink JM. Phenytoin cream for the treatment of neuropathic pain: case series. Pharmaceuticals. 2018;11(2). doi: $10.3390 / \mathrm{ph} 11020053$

11. Kopsky DJ, Keppel Hesselink JM. Single-blind placebo-controlled response test with phenytoin $10 \%$ cream in neuropathic pain patients. Pharmaceuticals. 2018;11(4):122. doi:10.3390/ph11040122

12. Keppel Hesselink JM, Kopsky DJ. The individualized N-of-1 trial: dose-response in a single-blind cross-over response test of phenytoin $10 \%$ and $30 \%$ cream in neuropathic pain. EC Anaesthesia. 2018;4 (6):1-6.
13. Kopsky DJ, Keppel Hesselink JM. A single-blind n-of-1 study evaluating 4 different doses of phenytoin in a topical analgesic cream for the treatment of peripheral neuropathic pain. Pain Manage Ther. 2018;2(1):17-20.

14. Erdmann PG, van Genderen FR, Teunissen LL, et al. Pain in patients with chronic idiopathic axonal polyneuropathy. Eur Neurol. 2010;64 (1):58-64. doi:10.1159/000315037

15. Walczak JS, Pichette V, Leblond F, Desbiens K, Beaulieu P. Behavioral, pharmacological and molecular characterization of the saphenous nerve partial ligation: a new model of neuropathic pain. Neuroscience. 2005;132(4):1093-1102. doi:10.1016/j.neuroscience. 2005.02.010

16. Walczak JS, Pichette V, Leblond F, Desbiens K, Beaulieu P. Characterization of chronic constriction of the saphenous nerve, a model of neuropathic pain in mice showing rapid molecular and electrophysiological changes. $J$ Neurosci Res. 2006;83 (7):1310-1322. doi:10.1002/jnr.20821

17. Regnard C, Twycross R, Mihalyo M, Wilcock A. Loperamide. J Pain Symptom Manage. 2011;42(2):319-323. doi:10.1016/j.jpainsymman. 2011.06.001

18. DeHaven-Hudkins DL, Burgos LC, Cassel JA, et al. Loperamide (ADL 2-1294), an opioid antihyperalgesic agent with peripheral selectivity. J Pharmacol Exp Ther. 1999;289(1):494-502.

19. Harochaw G. Relief of neuropathic pain with topical combinations. RXTriad. 2003;6(12):1-2.

20. Heneghan KC, inventor; Rush University Medical Center, assignee. Topical compositions providing pain relief and methods of use thereof. United States Patent US 20180318279. 2018 Nov 8.

21. Nozaki-Taguchi N, Yaksh TL. Characterization of the antihyperalgesic action of a novel peripheral mu-opioid receptor agonist-loperamide. Anesthesiology. 1999;90(1):225-234.

22. Junger H, Moore AC, Sorkin LS. Effects of full-thickness burns on nociceptor sensitization in anesthetized rats. Burns. 2002;28 (8):772-777.

23. Cheng B, Liu HW, Fu XB, Sheng ZY, Li JF. Coexistence and upregulation of three types of opioid receptors, mu, delta and kappa, in human hypertrophic scars. $B r J$ Dermatol. 2008;158 (4):713-720. doi:10.1111/j.1365-2133.2008.08449.x

24. Stein C, Machelska H. Modulation of peripheral sensory neurons by the immune system: implications for pain therapy. Pharmacol Rev. 2011;63(4):860-881. doi:10.1124/pr.110.003145

25. Keppel Hesselink JM, Kopsky DJ, Bhaskar AK. Ethical justification of single-blind and double-blind placebo-controlled response tests in neuropathic pain and N-of-1 treatment paradigm in clinical settings. J Pain Res. 2019;12:345-352. doi:10.2147/JPR.S180792
Journal of Pain Research

\section{Publish your work in this journal}

The Journal of Pain Research is an international, peer reviewed, open access, online journal that welcomes laboratory and clinical findings in the fields of pain research and the prevention and management of pain. Original research, reviews, symposium reports, hypothesis formation and commentaries are all considered for publication. The manuscript management system is completely online and includes a very quick and fair peer-review system, which is all easy to use. Visit http:// www.dovepress.com/testimonials.php to read real quotes from published authors. 